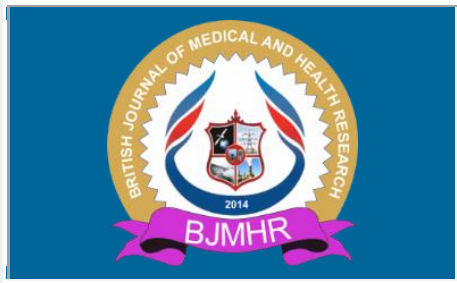

\title{
BJMHR
}

British Journal of Medical and Health Research

Journal home page: www.bjmhr.com

\section{Removable Overdenture versus fixed Bridge fabricated on all-on- 4 implants using CAD/CAM technology (Strain Gauge Analysis)}

\author{
Karim Osama Kamal Elnabarawy ${ }^{1}$, *, Ahmed Emad Eldin El Damarisy ${ }^{2}$, Marwa \\ Kothayer $^{3}$, Fardos Nabil Rizk ${ }^{4}$, Marwa Ezzat Sabet ${ }^{5}$ \\ 1. B.D.S, Faculty of Dentistry, Ain Shams University. Demonstrator of Oral and \\ Maxillofacial Prosthodontics, Faculty of Dentistry, British University in Egypt. \\ 2. Lecturer of Oral and Maxillofacial Prosthodontics, Faculty of Dentistry, British \\ University in Egypt. \\ 3. Associate Professor of Oral and Maxillofacial Prosthodontics, Faculty of Dentistry, Ain \\ shams University, Cairo, Egypt. \\ 4. Professor and Head of Oral and Maxillofacial Prosthodontics, Faculty of Dentistry, \\ British University in Egypt. \\ 5. Professor of Oral and Maxillofacial Prosthodontics, Faculty of Dentistry, Ain Shams \\ University, Cairo, Egypt
}

\section{ABSTRACT}

Assessing the effects on maxilla when using fixed vs. removable prosthesis on All-On- $4^{\circledR}$ protocol. This in-vitro study was conducted to compare stresses induced on distal implants in All-On- $4{ }^{\circledR}$ concept, between digitally constructed removable overdenture and fixed bridge, using strain gauge analysis. Four dummy implants were placed in their designed locations according to the All-On- $4{ }^{\circledR}$ concept; in a 3D printed completely edentulous maxillary acrylic cast. Multiunit abutments were secured to the implants. Two groups were defined: Group A: in which the framework was cemented to the four titanium copings over the implants (Fixed bridge). Group B: in which the same framework was picked up after relief was done and then seated on the ball attachments (Removable overdenture). Stresses were measured using strain gauges installed in their designed sites in the 3D printed cast. Loads of $100 \mathrm{~N}$ were applied in a vertical and oblique direction on the right molar area. Paired t test was used to compare between two different load directions within the same group and unpaired t test was used to compare between different groups. P-value $\leq 0.05$ was statistically significant. Group A with vertical loads $(532 \pm 9.2)$ and oblique loads $(464 \pm 40.3)$ showed significantly higher stresses on the supporting structures of the distal implants than group B with vertical loads $(64 \pm 7.75)$ and oblique loads $(41.5 \pm 2.42)$. Within group A, higher microstrains were recorded on the distal implants in the loaded side in case of applying vertical loads $(532 \pm 9.2)$ than in case of oblique loads $(464 \pm 40.3)$. Also, lower microstrains were recorded in the unloaded side in case of vertical loads $(21.5 \pm 2.42)$ than in case of oblique loads $(43 \pm 2.58)$. Within group B, higher microstrains were recorded in the loaded side in case of applying vertical loads $(64 \pm 7.75)$, than in case of oblique loads $(41.5 \pm 2.42)$. Also, lower microstrains were recorded in the unloaded side in case of vertical loads $(10.5 \pm 1.58)$ than in case of oblique loads (18.5 \pm 2.42$)$. Within the limitations of this study, it could be concluded that, the distal implants in the fixed bridge suffered higher loads than the removable overdenture.

Keywords: All-on-4 protocol, digitally constructed prostheses, Polyetheretherketone and strain gauge.

*Corresponding Author Email: karim.elnabarawy@ bue.edu.eg

Received 05 November 2021, Accepted 02 December 2021

Please cite this article as: Elnabarawy KO et al., Removable Overdenture versus fixed Bridge fabricated on all-on-4 implants using CAD/CAM technology (Strain Gauge Analysis). British Journal of Medical and Health Research 2021. 


\section{INTRODUCTION}

Complete edentulism is a worldwide predicament, especially in age 65 and older, which still represents a tremendous healthcare responsibility ${ }^{1,2,3}$. This condition may lead to disabilities and changes that cause poorer quality of life ${ }^{3,4}$. Conventional complete denture treatment has previously been the standard of care for completely edentulous patients ${ }^{5}$.

Since Conventional dentures have many drawbacks ${ }^{7,8,9}$, multiple literatures showed significant improvements in the quality of life of edentulous patients treated with osseointegrated dental implants ${ }^{5,6,7}$.

Placing dental implants of standard length in atrophic edentulous is almost impossible to place without needing complex surgical procedures such as bone augmentation, maxillary sinus floor elevation, and inferior alveolar nerve trans-positioning 12,13,14,15,16. The problems with these surgical procedures include: technical difficulties that require a skillful operator, increased cost for patients, prolonged treatment time, and postoperative complications as graft failure, infection, limited bone increase, and sinusitis. ${ }^{17,18,19,20,21,22,23}$

The All-On- $4^{\circledR}$ concept is a savior in atrophic ridges as it maximizes the use of available bone and allows immediate function ${ }^{20,21,22,23,24}$. Furthermore, All-On-4® implants reduce the overall treatment time, cost, and patient morbidity as it does not require additional surgical procedures as bone augmentation or a second stage surgery ${ }^{23,24}$. Implant prostheses are either fixed (fixed bridges) or removable (removable overdentures). Each type of prosthesis uses different attachments as the method of retention ${ }^{25,26}$. Reactions of the supporting structures around dental implants vary according to many factors such as: material of prosthesis, amount of load exerted, type of occlusion and attachment type (fixed or removable) ${ }^{27,28,38}$.

The use of computer-aided design and computer-aided manufacturing (CAD/CAM) technology introduced new materials in implant dentistry. When compared to conventional manufacturing methods, these materials could be milled to fabricate dental prostheses frameworks with more accuracy, precision of fit as it eliminates distortion and fewer fabrication steps ${ }^{30,31,32}$. The material for constructing complete implant overdenture frameworks may affect the absorption and distribution of chewing loads on implants and may influence the strain on surrounding bone ${ }^{33}$.

A modified Polyetheretherketone (PEEK) based polymer with 20\% ceramic fillers called Bio high performance polymer "BioHPP ${ }^{\circledR}$ " $\left(\right.$ Bredent $\left.^{\circledR} \mathrm{GmbH}\right)$ has been recently introduced in dentistry. BioHPP ${ }^{\circledR}$ provides excellent biocompatibility, good mechanical behavior, hightemperature resistance, and chemical stability. It became very popular as implant overdenture framework material due to its favorable properties ${ }^{33,34}$.

This in-vitro study was conducted to compare stresses induced on distal implants in All-On- 
$4^{\circledR}$ concept, between digitally constructed removable overdenture and fixed bridge, using strain gauge analysis.

The first null hypothesis assumed that there is no difference in stresses around the distal implants between the fixed bridge and removable overdenture.

The second null hypothesis assumed that there is no difference in stresses around the distal implants between the application of vertical and oblique loads on either the fixed bridge or the removable overdenture.

\section{MATERIALS AND METHOD}

This in-vitro study was conducted using a 3D model simulating a completely edentulous maxillary arch with two parallel implants placed in the anterior region and two angulated implants in the posterior region (All-On $-4^{\circledR}$ concept) to support maxillary fixed and removable prosthesis. A BioHPP ${ }^{\circledR}$ framework and polymethylmethacrylate "PMMA" crowns were digitally fabricated on the model.

A scan of completely edentulous maxillary model, used for educational purposes, was done via desktop scanner (3Shape ${ }^{\circledR}$ desktop scanner, Denmark), and then an STL file was generated.

In this file four implant beds were designed by Meshmixer ${ }^{\circledR}$ software (Autodesk Inc. California, USA) indicating the sites planned for the future implants with dimensions of $3.7 \times 11.5 \mathrm{~mm}$, two parallel vertical implants at equal distances from the midline between upper canine and lateral incisor, two angulated implants at 30 degrees between upper second premolar and first molar. In addition, two grooves were planned $1 \mathrm{~mm}$ distal to posterior implants for the attachment of the strain gauge. A 2-mm layer thickness was planned in the design on the model crest, which represented the future mucosa. The STL file was then sent to the additive 3D printer device (Dent2 Mogassam, LLC Co. Cairo, Egypt) and the model was printed.

Four crestal dummy implants (Reactive, Implant direct, USA) were inserted according to the "All on 4" concept in their designed sites.

Undercuts in future mucosa site were blocked using modeling base plate wax. (Cavex set up regular modeling wax, Holland). The 3D model was duplicated using dental stone (Elite stone, Zhermack SpA, Italy). A hard vacuum clear stent was made closely fitting over the stone model. An addition silicone material, Multisil-mask soft (Bredent, Senden, Germany) was injected directly into the space of the future mucosa on the 3D model with the clear stent in place until complete setting of the material.

Two straight and two 30 degree angled multiunit abutments were selected. The multiunit abutments and fixed titanium copings (Reactive, Implant direct, USA) were screwed to the 
implants on the model. The model was scanned using 3D scanner (CS.NEO, CAD Star Dental, Austria). The design of the BioHPP ${ }^{\circledR}$ framework was done using 3D software system (Exocad $^{\circledR}, \mathrm{GmbH}$, Germany). (Figure 1)

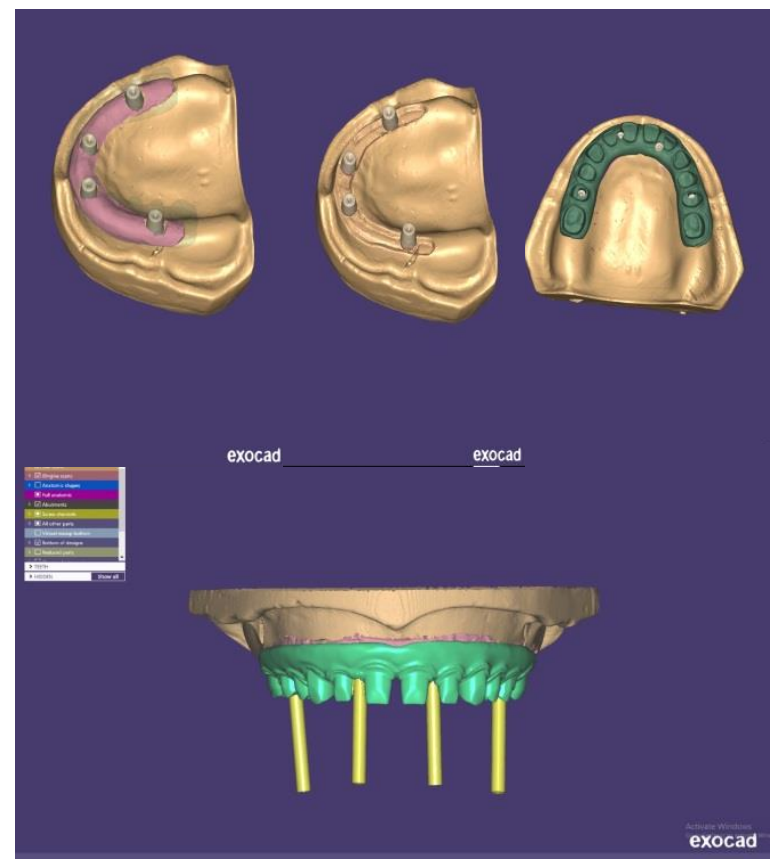

Figure 1: Design of BioHPP framework on Exocad software

Dry milling (Roland DGA, Hamamatsu, Japan) of the BioHPP ${ }^{\circledR}$ blank (Bre.CAM, Bredent, Senden, Germany) was done according to the 3D design. The holding sprues were separated from the framework after milling. Finally, the framework was finished and polished. The design of the crowns was done using software (Exocad GmbH, Germany) and then milled using high-impact polymethylmethacrylate (PMMA) blank (Bredent, Senden, Germany).

The framework and fitting surfaces of the PMMA crowns were sandblasted with $110-\mu \mathrm{m}$ grain Aluminum oxides at a pressure of 2 to $3 \mathrm{bar}$, then cleaned using alcohol and a clean brush according to the manufacturer's instructions. A thin coating of Visio. link (Bredent, Senden, Germany) was applied and cured for 90 seconds in the Bre.Lux light polymerization device (Bredent, Senden, Germany).

The PMMA teeth were cemented to the framework using dual cured resin cement (Panavia SA cement. Kurary Medical Inc., Tokyo, Japan). The teeth were cemented guided by a silicone key index made to accurately maintain teeth position during cementation.

Different shades of light cured Crea.lign composites (Bredent, Senden, Germany) were applied to the framework to mimic gingival color and contour then light polymerized. A Bre. Lux LED N2 hand lamp (Bredent, Senden, Germany) for fixation of the layers was used in intermediate polymerization for 15 seconds. Final polymerization was done in the Bre.Lux light-curing unit for 360 seconds for Crea.lign gingiva material. Finally, the framework was finished by a tungsten carbide bur and polished with a goat-hair brush and Acrypol (Bredent, Senden, Germany) or pumice. (Figure 2) 


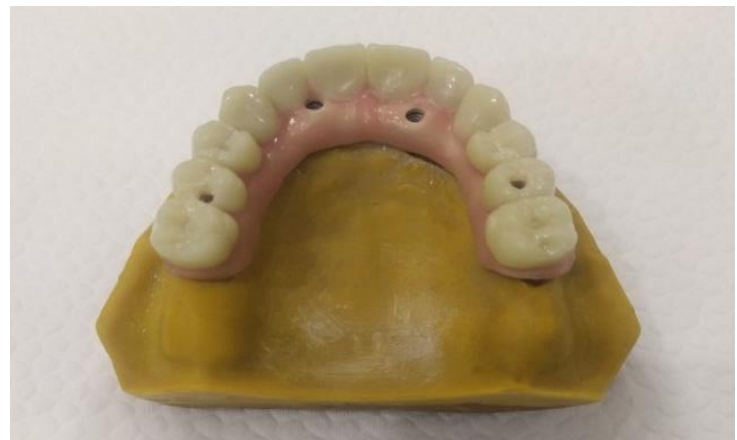

Figure 2: The finished framework cemented to the titanium copings on the 3D printed cast

The test groups were divided according to the type of attachment into:

Group A: The framework was cemented to the four titanium copings over the implants to be tested as the fixed bridge.

Group B: The same framework was picked up after relief was done and then seated on the ball attachments to be tested as the removable overdenture.

Two strain gauges (Kyowa electronic instrument co, LTD Tokyo, Japan) $1 \mathrm{~mm}$ in length, $2.4 \mathrm{~mm}$ in width and $120-\mathrm{Ohm}$ nominal resistance were installed in their grooves on the distal aspect parallel to the long axes of the two posterior implants. All strain gauges were bonded in position on the model with delicate layer of Cyano-Acrylate adhesive cement (Kyowa electronic instrument co, LTD Tokyo, Japan). The cast with the prosthesis to be tested was tightened into place following the manufacturer's recommendations.

The titanium copings were sandblasted and cemented to the fitting surface of the prosthesis using resin cement. The whole prosthesis was screwed to the multiunit abutments on the model. The 3D model with the fixed bridge was placed on the lower metal plate of the universal testing machine. (Figure 3)

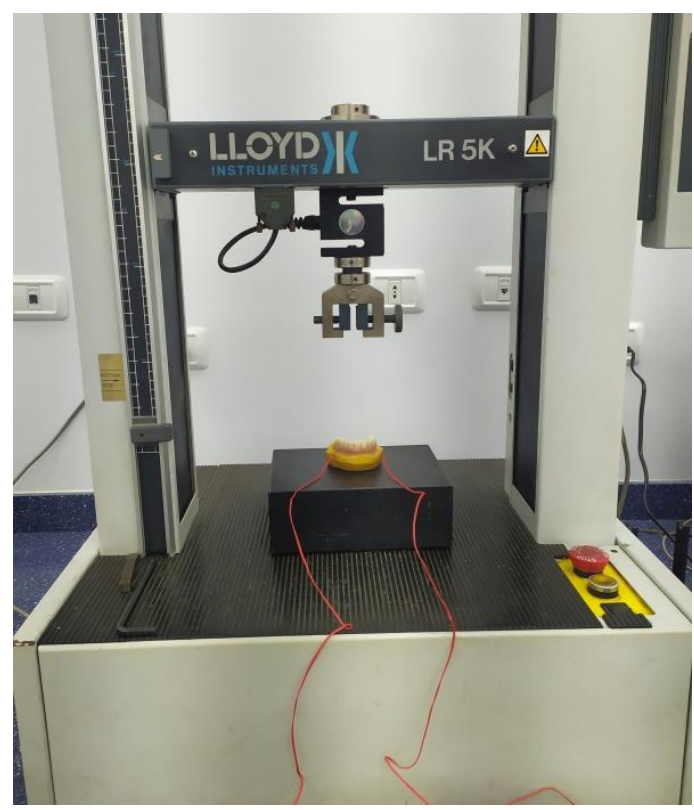

Figure 3: The prosthesis seated on the universal testing machine ready for testing. 
Vertical unilateral load was applied using chisel shaped load applicator connected to the universal testing machine. A load of $100 \mathrm{~N}$ was applied at the right first molar area. Fifteen minutes were given to the strain gauges to be in zero balance and the same load was repeated six times. The microstrains of the strain gauges were recorded to measure strains developed at the distal walls of the terminal implants during vertical unilateral load application. Finally, the microstrain readings were transferred to microstrain units from the four-channel strain meter.

The same steps were repeated for oblique unilateral loading after placing the model on a dental surveyor table angled 45 degrees.

The fixed bridge was unscrewed from the multiunit abutments using screwdriver. The titanium copings were removed from the fitting surface of the prosthesis using a small sized straight fissure bur. The ball attachments with their nylon caps (Reactive, Implant direct, USA) were fixed to the multiunit abutments. Proper relief was done in the fitting surface of prosthesis using an acrylic stone to create space for ball attachments and nylon caps. Undercuts were blocked using Liquidam material (Opaldam, Ultradent, South Jordan). The framework was picked-up by minimum shrinkage pick up material (Tokuyama Rebase II Fast, Tokuyama Dental Corp., Japan). Finally, finishing and polishing was done.

The same steps of testing the fixed bridge were repeated for the removable overdenture.

\section{Statistical Analysis}

The results were collected and statistically analyzed. The collected data were tested for normality by checking distribution of data and calculating the mean values. Numerical data were presented by mean and standard deviation (SD). Paired t test was used to compare between two different load directions within the same group and unpaired t test was used to compare between different groups. The significance level was set at $\mathrm{P} \leq 0.05$.

\section{RESULTS AND DISCUSSION}

\section{Effect of vertical and oblique unilateral loads on the distal implant supporting structures within group A:}

Within group A (fixed bridge), higher microstrains were recorded on the distal implants in the loaded side in case of applying vertical loads (532 \pm 9.2$)$ than in case of applying oblique loads $(464 \pm 40.3)$

Furthermore, lower microstrains were recorded in the unloaded side in case of vertical loads $(21.5 \pm 2.42)$ than in case of oblique loads $(43 \pm 2.58)$. However by using t-test, these differences were statistically significant. (Table 1) 
Table 1: Means, standard deviations and P-values of t-test for microstrains after vertical and oblique unilateral loads within group $A$.

\begin{tabular}{|c|c|c|c|c|c|c|}
\hline & \multicolumn{2}{|c|}{ Vertical load } & \multicolumn{2}{|c|}{ Oblique load } & \multirow[b]{2}{*}{ P-value } \\
\hline & & Mean & SD & Mean & SD & \\
\hline Group A & Loaded Side & 532.5 & 9.2 & 464 & 40.3 & $<0.001$ \\
\hline & Unloaded Side & 21.5 & 2.42 & 43 & 2.58 & $<0.001$ \\
\hline
\end{tabular}

II. Effect of vertical and oblique unilateral loads on the distal implant supporting structures within group B:

Within group B (removable overdenture), higher microstrains were recorded on the distal implants in the loaded side in case of applying vertical loads (64 \pm 7.75$)$, than in case of applying oblique loads (41.5 \pm 2.42$)$. Furthermore, lower microstrains were recorded in the unloaded side in case of vertical loads $(10.5 \pm 1.58)$ than in case of oblique loads $(18.5 \pm 2.42)$. However by using t-test, these differences were statistically significant. (Table 2)

Table 2: Means, standard deviations and P-values of t-test for microstrains after vertical and oblique unilateral loads within group $B$.

\begin{tabular}{lllllll}
\hline & & \multicolumn{3}{c}{ Vertical load } & \multicolumn{3}{c}{ Oblique load } & \\
& & Mean & SD & Mean & SD & P-value \\
\hline Group B & Loaded Side & 64 & 7.75 & 41.5 & 2.42 & $<0.001$ \\
& Unloaded Side & 10.5 & 1.58 & 18.5 & 2.42 & $<0.001$ \\
\hline
\end{tabular}

III. Effect of vertical unilateral load on the distal implant supporting structures in both groups:

During vertical unilateral load higher microstrains were recorded on the distal implant in the

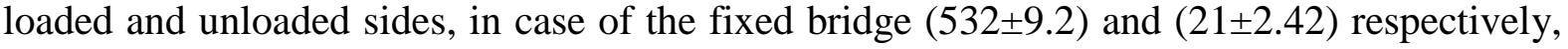
than in case of the removable overdenture $(64 \pm 7.75)$ and $(10.5 \pm 1.58)$ respectively. However, by using t-test these differences were statistically significant. (Table 3 )

Table 3: Means, standard deviations and P-values of t-test for microstrains after vertical unilateral loads on both groups.

\begin{tabular}{lllllll}
\hline & & Group A & Group B & \\
& & Mean & SD & Mean & SD & P-value \\
\hline Vertical load & Loaded Side & 532.5 & 9.2 & 64 & 7.75 & $<0.001$ \\
& Unloaded Side & 21.5 & 2.42 & 10.5 & 1.58 & $<0.001$ \\
\hline
\end{tabular}

IV. Effect of oblique unilateral load on the distal implant supporting structures in both groups:

During oblique unilateral load higher microstrains were recorded on the distal implant in the

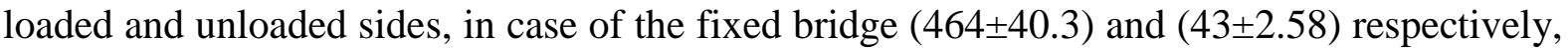

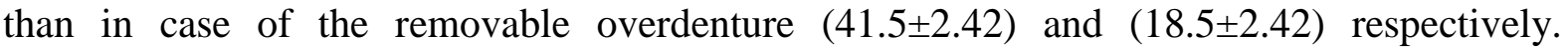
However, by using t-test these differences were statistically significant. (Table 4) 
Table 4: Means, standard deviations and P-values of t-test for microstrains after oblique unilateral loads on both groups.

\begin{tabular}{|c|c|c|c|c|c|c|}
\hline & \multicolumn{2}{|c|}{ Group A } & \multicolumn{2}{|c|}{ Group B } & \multirow[b]{2}{*}{ P-value } \\
\hline & & Mean & SD & Mean & SD & \\
\hline \multirow[t]{2}{*}{ Oblique load } & Loaded side & 464 & 40.3 & 41.5 & 2.42 & $<0.001$ \\
\hline & Unloaded side & 43 & 2.58 & 18.5 & 2.42 & $<0.001$ \\
\hline
\end{tabular}

Some patients were reported to benefit more from removable implant overdenture prosthesis than a fixed prosthesis. For example, elderly patients who have difficulty performing oral hygiene measures and patients with parafunctional habits as the denture is removed at night which, decreases stresses to the implants and bone ${ }^{35,36,37,38}$. Moreover, removable prostheses are more easily repaired in comparison to fixed ones ${ }^{37}$. However, several studies reported that overdentures needed adjustments and corrections after delivery of the prostheses. The most commonly identified issue was the loosening of the retentive mechanisms ${ }^{39,40}$.

The All-on-4 concept was used in this study as it has many biomechanical advantages. These advantages include increasing Antero-posterior (AP) spread, better load distribution alongside cross-arch stabilization, shorter cantilever, using longer implants by tilting them posteriorly, and preventing excessive forces that may cause marginal bone loss ${ }^{41}$.

The implant prosthesis framework was digitally constructed via CAD/CAM technology as it produces prosthesis with superior qualities compared to conventional methods of fabrication $^{42,43}$.

In this study, the stresses induced by the removable prosthesis were lower when compared to the fixed prosthesis during vertical and oblique forces. This result may be due to the resilient ball attachment in the removable prosthesis that allows movement of the prosthesis and, therefore, dissipation of forces falling on the implants. This result is consistent with the clinical study by Mazaro et $\mathrm{al}^{44}$ that using O-ring attachments distributes the load and decreases the load around implants compared to fixed implant overdentures. Moreover, the result mentioned was following Nogueira et al. ${ }^{45}$, who reported lower tensile stresses on implant-supported overdenture, despite an increased risk of prosthesis fracture and more frequent maintenance visits. This result was also confirmed by Suzuki Y. et al. ${ }^{46}$, who concluded that using a stress-breaking ball attachment in implant overdentures distributes the occlusal force equally between implants and residual ridge.

On the contrary, the fixed attachment does not allow such movement due to the minimal resilience of the cement holding the restoration. It was reported that there is an uneven force distribution on implants in the fixed implant-supported prosthesis, with higher stress concentration in the bone-implant interface adjacent to the cantilever extension ${ }^{47}$. It has been proposed that an excessive force on the bone may lead to bone loss around implants ${ }^{48}$. More 
recent studies reported that peri-implantitis and prosthesis complications occurred with fixed implant overdentures and both increased over time specifically after ten years ${ }^{49}$.

In this study, the vertical loads falling on the distal implants on the loaded side were higher than the oblique loads in both groups. This result can be explained by a rule of mechanics that states $^{50}$ : Any force can be resolved into two components, which are either perpendicular to or inclined to each other." So, the vertical forces are primarily transmitted axially to the distal surface of implant supporting structures. In contrast, the oblique forces are resolved into two components vertical and horizontal, which decreasing the stresses on the implant supporting structures.

A different finding was found in a study by Sedat Guven et al. ${ }^{51}$, which concluded that the stress values with oblique loading forces were higher than with vertical loading forces for the implants and the zirconia frameworks. Furthermore, the zirconia frameworks showed higher stress values than the titanium structures. This result could be explained by the fact that zirconia has a higher elastic modulus than titanium. The difference in our current study could be explained by the fact that $\mathrm{BioHPP}^{\circledR}$ used has a lower elastic modulus than zirconia and has an off-peak property as it offers an elastic behavior close to that of bone and reduces detrimental stresses on implants ${ }^{52}$. Considering the fact that vertical stresses along the long axis of implants are less harmful than oblique stresses ${ }^{53}$.

Based on the previous findings, the first null hypothesis of this study is rejected because the stresses on the distal implants in the fixed bridge were higher statistically compared to the removable overdenture.

Additionally, the second null hypothesis is rejected because the stresses on the distal implants on the loading side when applying vertical loads were higher statistically than when applying oblique loads in both groups.

\section{CONCLUSION}

Within the limitations of this study, it could be concluded that the use of removable prosthesis might be more favorable than using fixed bridges when All-On- $4^{\circledR}$ protocol was used.

\section{REFERENCES}

1. Felton DA. Edentulism and comorbid factors. J Prosthodont. 2009;18(2):88-96.

2. Ribeiro CG, Cascaes AM, Silva AER, Seerig LM, Nascimento GG, Demarco FF. Edentulism, severe tooth loss and lack of functional dentition in elders: A study in Southern Brazil. Braz Dent J. 2016;27(3):345-52.

3. Elham Emami et al. The Impact of Edentulism on Oral and General Health.International Journal f Dentistry. 2013;2013:7. 
4. Peltzer K, Hewlett S, Yawson AE, Moynihan P, Preet R, Wu F, et al. Prevalence of loss of all teeth (Edentulism) and associated factors in older adults in China, Ghana, India, Mexico, Russia and South Africa. Int $\mathrm{J}$ Environ Res Public Health. 2014;11(11):11308-24.

5. Babbush CA, Kirsch A, Mentag PJ, Hill B, Intramobile Cylinder (IMZ) Two-Stage Osteointegrated Implant System With the Intramobile Element (IME): Part I. Its Rationale and Procedure for Use, Int J Oral Maxillofac Implants, 2 (1987) 203-216.

6. Jethlia H, Jethlia A, Naveen RP, Meshram A, Sharma N. Post insertion problems and their management in complete denture. J Evol Med Dent Sci 2013;2:194-200.

7. Ikebe K, Matsuda KI, Morii K, Furuya-Yoshinaka M, Nokubi T, Renner RP. Association of masticatory performance with age, posterior occlusal contacts, occlusal force, and salivary flow in older adults. Int J Prosthodont 2006;19:475-81.

8. Ikebe K, Amemiya M, Morii K, Matsuda KI, Furuya-Yoshinaka M, Yoshinaka M, et al. Association between oral stereognostic ability and masticatory performance in aged complete denture wearers. Int J Prosthodont 2007;20:245-50.

9. Koshino H, Hirai $\mathrm{T}$, Ishijima $\mathrm{T}$, Ikeda $\mathrm{Y}$. Tongue motor skills and masticatory performance in adult dentates, elderly dentates, and complete denture wearers. J Prosthet Dent 1997;77:147-52.

10. Oh SH, Kim Y, Park JY, Jung YJ, Kim SK and Park SY: Comparison of fixed implant supported prosthesis, removable implant supported prosthesis, and complete dentures: patient satisfaction and oral health-related quality of life. Clin Oral Implants Res. 2016.

11. Sharma AJ, Nagrath R, Lahori M. A comparative evaluation of chewing efficiency, masticatory bite force, and patient satisfaction between conventional denture and implant-supported mandibular overdenture: An in vivo study. J Indian Prosthodont Soc $2017 ; 17$ :

12. Schropp L, Wenzel A, Kostopoulos L, Karring T. Bone healing and soft tissue contour changes following single-tooth extraction: a clinical and radiographic 12month prospective study. Int J Periodontics Restorative Dent. 2003; 23(4): 313- 323.

13. Chappuis V, Araújo MG, Buser D. Clinical relevance of dimensional bone and soft tissue alterations post-extraction in esthetic sites. Periodontol 2000. 2017; 73(1): 73 83.

14. Ravida A, Wang IC, Sammartino G, et al. Prosthetic rehabilitation of the posterior atrophic maxilla, short $(\leq 6 \mathrm{~mm})$ or long $(\geq 10 \mathrm{~mm})$ dental implants? A systematic review, meta-analysis, and trial sequential analysis: Naples consensus report working group a. 
15. Yan Q, Wu X, Su M, Hua F, Shi B. Short implants $(\leq 6 \mathrm{~mm})$ versus longer implants with sinus floor elevation in atrophic posterior maxilla: a systematic review and metaanalysis. BMJ Open. 2019; 9(10):e029826.

16. Ravidà AMJ, Alassadi M, Saleh MH, Askar H, Wang HL. Impact of implant length on survival of rough-surface implants in nonaugmented posterior areas: a systematic review and meta-regression analysis. J Oral Maxillofac Implants. 2019; 34: 13591369.

17. Starch-Jensen T, Aludden H, Hallman M, Dahlin C, Christensen AE, Mordenfeld A. A systematic review and meta-analysis of long-term studies (five or more years) assessing maxillary sinus floor augmentation. Int J Oral Maxillofac Surg. 2018; 47(1): 103- 116.

18. Lee SA, Lee CT, Fu MM, Elmisalati W, Chuang SK. Systematic review and metaanalysis of randomized controlled trials for the management of limited vertical height in the posterior region: short implants $(5$ to $8 \mathrm{~mm}$ ) vs longer implants $(>8 \mathrm{~mm}$ ) in vertically.

19. Bechara S, Kubilius R, Veronesi G, Pires JT, Shibli JA, Mangano FG. Short (6-mm) dental implants versus sinus floor elevation and placement of longer $(\geq 10-\mathrm{mm})$ dental implants: a randomized controlled trial with a 3-year follow-up. Clin Oral Implants Res. .

20. Chirila L, Rotaru C, Filipov I, Sandulescu M. Management of acute maxillary sinusitis after sinus bone grafting procedures with simultaneous dental implants placement - a retrospective study. BMC Infect Dis. 2016; 16(Suppl 1):94.

21. Thoma DS, Haas R, Tutak M, Garcia A, Schincaglia GP, Hammerle CHF. Randomized controlled multicentre study comparing short dental implants $(6 \mathrm{~mm})$ versus longer dental implants $(11-15 \mathrm{~mm})$ in combination with sinus floor elevation procedures. Part 1: demogr.

22. Hernandez-Alfaro F, Torradeflot MM, Marti C. Prevalence and management of Schneiderian membrane perforations during sinus-lift procedures. Clin Oral Implants Res. 2008; 19(1): 91- 98.

23. Esposito M, Buti J, Barausse C, Gasparro R, Sammartino G, Felice P. Short implants versus longer implants in vertically augmented atrophic mandibles: A systematic review of randomised controlled trials with a 5-year post-loading follow-up. Int J Oral Impl.

24. Malo P, Rangert B, Dvarsater L. Immediate function of Branemark implants in the esthetic zone: a retrospective clinical study with 6 months to 4 years of follow-up. Clin Implant Dent Relat Res. 2000;2:138-46. 
25. Maló P, Rangert B, Nobre M. All-on-4 immediate-function concept with Brånemark System implants for completely edentulous maxillae: a 1-year retrospective clinical study. Clin Implant Dent Relat Res. 2005;7 Suppl 1:S88-94. doi: 10.1111/j.17088208.2005.tb0.

26. Malo P, Friberg B, Polizzi G, Gualini F, Vighagen T, Rangert B. Immediate and early function of Branemark System implants placed in the esthetic zone: a 1-year prospective clinical multicenter study. Clin Implant Dent Relat Res 2003;5:37-46.

27. Capelli M, Zuffetti F, Del Fabbro M, Testori T. Immediate rehabilitation of the completely edentulous jaw with fixed prostheses supported by either upright or tilted implants: a multicenter clinical study. Int J Oral Maxillofac Implants. 2007;22(4):63964.

28. Maló P, de Araújo Nobre M, Lopes A, Ferro A, Gravito I. All-on-4® Treatment Concept for the Rehabilitation of the Completely Edentulous Mandible: A 7-Year Clinical and 5-Year Radiographic Retrospective Case Series with Risk Assessment for Implant Failure .

29. Simon H, Yanase RT. Terminology for implant prostheses. Int J Oral Maxillofac Implants 2003;18:539-543.

30. de Grandmont P, Feine JS, Taché R, et al. Within-subject comparisons of implantsupported mandibular prostheses: Psychometric evaluation. J Dent Res 1994;73:1096-1104.

31. Begg T, Geerts GA, Gryzagoridis J. Stress patterns around distal angled implants in the all-on-four concept configuration. Int J Oral Maxillofac Implants. 2009;24(4):663671.

32. Trakas T, Michalakis K, Kang K, Hirayama H. Attachment systems for implant retained overdentures: A literature review. Implant Dent 2006;15:24-34.

33. Fueki K, Kimoto K, Ogawa T, Garrett NR. Effect of implant-supported or retained dentures on masticatory performance: A systematic review. J Prosthet Dent 2007;98:470-477.

34. Torabi K, Farjood E, Hamedani S. Rapid Prototyping Technologies and their Applications in Prosthodontics, a Review of Literature. J Dent (Shiraz, Iran). 2015;16(1):1-9.

35. Miyazaki T, Hotta Y, Kunii J, Kuriyama S, Tamaki Y. A review of dental CAD/CAM: current status and future perspectives from 20 years of experience. Dent Mater J. 2009;28(1):44-56.

36. Preis V, Hahnel S, Behr M, Bein L, Rosentritt M. In-vitro fatigue and fracture testing of $\mathrm{CAD} / \mathrm{CAM}$-materials in implant-supported molar crowns. Dent Mater. 
2017;33(4):427-433. doi:10.1016/j.dental.2017.01.003.

37. Ciftçi Y, Canay S. Stress distribution on the metal framework of the implantsupported fixed prosthesis using different veneering materials. Int $\mathrm{J}$ Prosthodont. 2001;14(5):406-411.

38. Papathanasiou, I., Kamposiora, P., Papavasiliou, G. et al. The use of PEEK in digital prosthodontics: A narrative review. BMC Oral Health 20, 217 (2020). 10.1186/s12903-020-01202-7.

39. Carlsson GE, Kronström M, de Baat C et al. A survey of the use of mandibular implant overdentures in 10 countries. Int J Prosthodont 2004; 17: 211- 217.

40. Isaksson R, Becktor JP, Brown A, Laurizohn C, Isaksson S. Oral health and oral implant status in edentulous patients with implant-supported dental prostheses who are receiving long-term nursing care. Gerodontology. 2009;26(4):245-249. doi:10.1111/j.1741-2.

41. Sadowsky S, Zitzmann N. Protocols for the Maxillary Implant Overdenture: A Systematic Review. Int J Oral Maxillofac Implants. 2017;31:s182-91.

42. Kuoppala, R., Näpänkangas, R. and Raustia, A. (2012), Outcome of implantsupported overdenture treatment - a survey of 58 patients. Gerodontology, 29: e577e584. 10.1111/j.1741-2358.2011.00524.x.

43. Andreiotelli M, Att W, Strub JR. Prosthodontic complications with implant overdentures: a systematic literature review. Int J Prosthodont. 2010;23(3):195-203.

44. Johns RB, Jemt T, Heath MR, et al. A multicenter study of overdentures supported by Brånemark implants. Int J Oral Maxillofac Implants. 1992;7(4):513-522.

45. Chan MH, Holmes C. Contemporary "All-on-4" concept. Dent Clin North Am. 2015;59(2):421-470. doi:10.1016/j.cden.2014.12.001.

46. Örtorp A, Jemt T. CNC-milled titanium frameworks supported by implants in the edentulous jaw: a 10-year comparative clinical study. Clin Implant Dent Relat Res. 2012;14:88-99.

47. Eliasson A, Wennerberg A, Johansson A, Ortorp A, Jemt T. The precision of fit of milled titanium implant frameworks (I-Bridge) in the edentulous jaw. Clin Implant Dent Relat Res. 2010;12:81-90.

48. Mazaro JV, Filho HG, Vedovatto E, Pellizzer EP, Rezende MC, Zavanelli AC. Evaluation of stress patterns produced by implant-retained overdentures and implantretained fixed partial denture. J Craniofac Surg. 2011;22(6):2153-2157. doi:10.1097/SCS.0b013e318.

49. Nogueira, TE, Aguiar, FMO, de Barcelos, BA, Leles, CR. A 2-year prospective study of single-implant mandibular overdentures: Patient-reported outcomes and 
prosthodontic events. Clin Oral Impl Res. 2018; 29: 541- 550.

50. Suzuki Y, Ohkubo C, Kurtz KS. Clinical application of stress-breaking ball attachment for implant overdenture. J Prosthodont Res. 2013 Apr 1;57(2):140-4.

51. Aglietta, M., Siciliano, V.I., Zwahlen, M., Brägger, U., Pjetursson, B.E., Lang, N.P. and Salvi, G.E. (2009), A systematic review of the survival and complication rates of implant supported fixed dental prostheses with cantilever extensions after an obser.

52. Lindquist LW, Rockler B, Carlsson GE. Bone resorption around fixtures in edentulous patients treated with mandibular fixed tissue-integrated prostheses. J Prosthet Dent. 1988 Jan 1;59(1):59-63.

53. Papaspyridakos P, Chen CJ, Chuang SK, Weber HP, Gallucci GO. A systematic review of biologic and technical complications with fixed implant rehabilitations for edentulous patients. Int J Oral Maxillofac Implants. 2012;27(1):102-110.

54. DAN B. MARGHITU, Mechanical Engineer's Handbook, Academic Press, 2001, Pages 189-242, ISBN 9780124713703, Https://doi.org/10.1016/B978-0124713703/50005-X.

55. Guven, Sedat \& Atalay, Yusuf \& Asutay, Fatih \& Ucan, Musa \& Dundar, Serkan \& Karaman, Tahir \& Gunes, Nursin. (2015). Comparison of the effects of different loading locations on stresses transferred to straight and angled implant-supported zirconia framewo.

56. Iyer, Ruchika \& S.R, Suchitra \& Hegde, Divya \& Coutinho, Cora \& Priya, Akansha. (2020). Biohpp: Properties And Applications In Prosthodontics A Review. Journal of Research in Dentistry. 7. 72. 10.19177/jrd.v7e4201972-76.

57. Morneburg TR, Pröschel PA. Measurement of masticatory forces and implant loads: a methodologic clinical study. Int J Prosthodont.2002; 15(1):20-27.

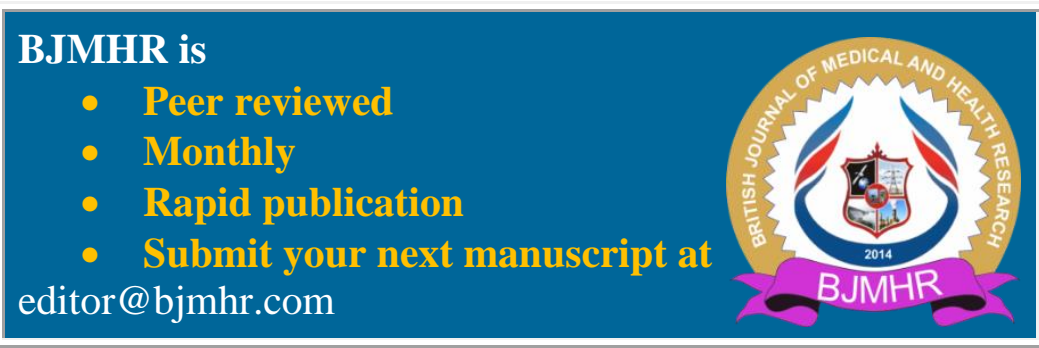

